\title{
Phase 1 study of trebananib (AMG 386), an angiogenesis targeting angiopoietin-1/2 antagonist, in Japanese patients with advanced solid tumors
}

\author{
Toshihiko Doi - Atsushi Ohtsu - Nozomu Fuse • Takayuki Yoshino • \\ Makoto Tahara • Kazuhiro Shibayama • Takatoshi Takubo • \\ David M. Weinreich
}

Received: 30 August 2012/ Accepted: 29 September 2012/Published online: 3 November 2012

(C) The Author(s) 2012. This article is published with open access at Springerlink.com

\begin{abstract}
Purpose To evaluate the safety, tolerability, pharmacokinetics, and antitumor activity of trebananib (AMG 386) - a first-in-class angiopoietin-1/2 antagonist peptide-Fc fusion protein-in Japanese patients, we conducted a phase 1, dose escalation study.

Methods Eligible patients were men or women, aged between 20 and 74 years, who had histologically or cytologically confirmed advanced solid tumors refractory to standard treatment. Trebananib (3, 10, and $30 \mathrm{mg} / \mathrm{kg}$ ) was administered intravenously over $60 \mathrm{~min}$ in weekly cycles.

Results From June 2009 to April 2010, a total of 18 patients ( 6 for each dose cohort) were enrolled into the study. Trebananib was tolerated at all dose levels. No dose-limiting toxicities were observed. The most common adverse events were peripheral edema, constipation, fatigue, and pyrexia. Exposure to trebananib appeared to increase according to the dose administered. Serum clearance appeared to be similar across the dose range with the mean terminal-phase half-life ranging from 93.9
\end{abstract}

T. Doi $(\bowtie) \cdot$ A. Ohtsu · N. Fuse · T. Yoshino · M. Tahara

National Cancer Center Hospital East, 6-5-1 Kashiwanoha,

Kashiwa, Chiba 277-8577, Japan

e-mail: tdoi@east.ncc.go.jp

K. Shibayama $\cdot$ T. Takubo

Takeda Bio Development Center Ltd., Sapia Tower,

1-7-12 Marunouchi, Chiyoda-ku, Tokyo 100-0005, Japan

D. M. Weinreich

Amgen Inc., One Amgen Center Drive, Thousand Oaks,

CA 91320-1799, USA to $95.9 \mathrm{~h}$. No neutralizing antibodies were detected. Tumor response was assessed in 18 patients. Of these, one patient with colon cancer in the $3-\mathrm{mg} / \mathrm{kg}$ cohort and one with bladder cancer in the $30-\mathrm{mg} / \mathrm{kg}$ cohort had partial responses as their best responses. These 2 patients were on treatment at the time of data cutoff (January 17, 2012).

Conclusion Trebananib was tolerated and showed acceptable safety profile in Japanese patients with advanced solid tumors. The pharmacokinetic profiles were similar to those in the previous studies in the United States. Trebananib also showed evidence of durable antitumor activity in some patients.

Keywords Trebananib - AMG 386 .

Angiopoietin 1/2-neutralizing peptibody .

Clinical trial, phase 1 . Pharmacokinetics · Safety

$\begin{array}{ll}\begin{array}{ll}\text { Abbreviations } \\ \text { VEGFR }\end{array} & \begin{array}{l}\text { Vascular endothelial growth factor } \\ \text { receptor }\end{array} \\ \text { Ang1 } & \text { Angiopoietin-1 } \\ \text { Ang2 } & \text { Angiopoietin-2 } \\ \text { PK } & \text { Pharmacokinetic } \\ \text { ECOG } & \text { Eastern Cooperative Oncology Group } \\ \text { AST } & \text { Aspartate aminotransferase } \\ \text { ULN } & \text { Upper limit of normal } \\ \text { ALT } & \text { Alanine aminotransferase } \\ \text { DLT } & \text { Dose-limiting toxicity } \\ \text { NCI CTCAE } & \text { National Cancer Institute Common } \\ & \text { Terminology Criteria for Adverse Events } \\ \text { sVCAM-1 } & \text { Soluble vascular cell adhesion molecule-1 } \\ C_{\text {max }} & \text { Maximum observed concentration } \\ \text { AUC } & \text { Area under the serum concentration-time } \\ & \text { curve from time 0 to 168 h post-dose }\end{array}$




\section{Introduction}

Angiogenesis is an essential process for tumor growth and metastasis [1, 2]. Unless angiogenesis occurs, tumor growth is limited because it is dependent on the continued supply of oxygen [3]. Thus, targeting angiogenesis represents one strategy for the development of anticancer therapies [4], and preclinical models of human cancer have shown that blocking angiogenesis inhibits proliferation of tumor and induces tumor regression [1, 4]. On the basis of these findings, several antiangiogenic agents have been developed and have already been approved for anticancer treatment. These agents include the inhibitors targeting vascular endothelial growth factor receptor (VEGFR) pathway [5, 6], such as monoclonal antibodies and tyrosine kinase inhibitors [7]. However, much attention has been focused on the clinical toxicity profile of these agents [8]. For example, they may increase the risk for several adverse events such as hypertension, proteinuria, coagulation disorders, and gastro-intestinal toxicity [8,9]. Under these circumstances, newer agents are needed.

One of these candidates is an agent that blocks the interaction of angiopoietins with Tie2 receptor [10, 11]. Angiopoietin-1 (Ang1) is an angiogenic factor that signals through the endothelial cell-specific Tie2 receptor tyrosine kinase [12]. Angiopoietin-2 (Ang2) is expressed only at sites of vascular remodeling, where it reduces vascular integrity and probably makes the endothelial cells more responsive to the proliferative signals of VEGF [12]. In experimental models of cancer, imbalances between Ang1 and Ang2 resulted in a net gain of Ang2 activity, and the over-expression of Ang2 led to enhanced tumor angiogenesis and growth [13]. In addition, dual inhibition of Ang1 and Ang2 resulted in better antitumor activity than inhibition of Ang2 alone, which suggests that dual Ang1/2 inhibition is superior to selective Ang2 inhibition for suppression of angiogenesis in some postnatal settings [14]. Thus, dual Ang1/2 inhibitors are expected to be effective in the treatment of various types of cancer.

Trebananib (AMG 386) is an investigational firstin-class angiopoietin antagonist peptide-Fc fusion protein. It reduces tumor angiogenesis by selectively inhibiting the interaction of Ang1 and Ang2 with the Tie2 receptor [15]. Recently, data from 2 phase 1 studies conducted in the United States became available. In these studies, weekly administration of trebananib showed acceptable safety profile and antitumor activity as monotherapy or in combination with 3 common chemotherapy regimens in patients with advanced solid tumors [16, 17].

However, these studies mainly included Caucasians and it is uncertain whether these findings are generalizable to other ethnic populations such as Asians. Accordingly, we conducted a phase 1 study in Japan. The primary objectives of the study were to evaluate the safety, tolerability, and pharmacokinetic (PK) profile of trebananib in Japanese patients with advanced solid tumors. The secondary objectives were to explore its efficacy and potential biomarkers.

\section{Methods}

Study design and ethical considerations

This phase 1, open-label, dose escalation study was conducted at National Cancer Center Hospital East in Japan. The study was conducted in accordance with the Declaration of Helsinki and Good Clinical Practice. Its protocol was reviewed and approved by the institutional review board of the hospital. All patients provided written informed consent prior to their inclusion in the study.

\section{Patient population}

Eligible patients were men or women, aged between 20 and 74 years, who had histologically or cytologically confirmed advanced solid tumor which was refractory to standard treatment or for which no curative treatment was available. Other inclusion criteria were Eastern Cooperative Oncology Group (ECOG) performance status of 0-1, normal sinus rhythm on electrocardiographic evaluation, and life expectancy of at least 3 months. Patients were also required to have adequate hematologic, renal, hepatic, and hemostatic function defined as follows: absolute neutrophil count $\geq 1,500 / \mu \mathrm{L}$; platelet count $\geq 100,000 / \mu \mathrm{L}$; hemoglobin $\geq 9 \mathrm{~g} / \mathrm{dL}$; creatinine clearance $>40 \mathrm{~mL} / \mathrm{min}$; urinary protein $\leq 30 \mathrm{mg} / \mathrm{dL}$ in urinalysis or $\leq 1+$ on dipstick; aspartate aminotransferase (AST) $\leq 2.5$ times the upper limit of normal (ULN) $(\leq 5$ times ULN for patients with liver metastases); alanine aminotransferase (ALT) $\leq 2.5$ times ULN ( $\leq 5$ times ULN for those with liver metastases); alkaline phosphatase $\leq 2.0$ times ULN ( $\leq 5$ times ULN for those with bone or liver metastases); total bilirubin $\leq 2.0$ times ULN; and prothrombin time or activated partial thromboplastin time $\leq 1.5$ times ULN.

Patients were excluded if they had any central nervous system tumors; hematologic malignancies; unresolved toxicities from prior anticancer therapy; clinically significant cardiovascular disease within 1 year before enrollment such as myocardial infarction, unstable angina, congestive heart failure (New York Heart Association class 2-4), peripheral vascular disease, cerebrovascular disorder, transient ischemic attack, or uncontrolled arrhythmia; uncontrolled hypertension (systolic $>150 \mathrm{~mm} \mathrm{Hg}$ or diastolic $>90 \mathrm{~mm} \mathrm{Hg}$ ); a history of arterial or venous thrombosis within 1 year; presence of ascites or pleural 
effusion requiring medical intervention; a history of bleeding diathesis or clinically significant bleeding within 6 months; non-healed wound, ulcer, or fracture; head and neck cancer; squamous cell tumor, or lung cancer with large central tumor lesions $\geq 3 \mathrm{~cm}$; infection with human immunodeficiency virus, hepatitis $\mathrm{C}$ virus, or hepatitis $\mathrm{B}$ virus; major surgery within 4 weeks; or minor surgical procedure, placement of central venous catheter, or fine needle aspiration within 7 days. Pregnant or breastfeeding women, women of childbearing potential or men having a partner of childbearing potential who were unwilling to use adequate contraceptive precautions during the study were also excluded.

\section{Study treatment}

Trebananib was administered intravenously over 60 ( \pm 15 ) min on days $1,8,15$, and 22 without premedication. Patients were enrolled sequentially into one of 3 dose cohorts $(3,10$, and $30 \mathrm{mg} / \mathrm{kg} ; 6$ patients for each cohort). The starting dose was $3 \mathrm{mg} / \mathrm{kg}$, which was determined on the basis of the first-in-human study conducted in the United States [16]. Initially, 6 patients received trebananib intravenously every week for up to 28 days, and dose escalation proceeded unless 2 or more patients had a doselimiting toxicity (DLT) during the first 28 days. Trebananib was not administered on day 29. For patients who had no DLTs and wished to continue the study treatment, trebananib was administered in weekly cycles after day 36.

DLT was defined as any treatment-related toxicity which met the following criteria during the first 28 days according to the National Cancer Institute Common Terminology Criteria for Adverse Events (NCI CTCAE) version 3.0: grade 4 or greater hematologic toxicity; grade 3 or greater nonhematologic toxicity other than AST, ALT, and infusion reactions; and AST or ALT $>10$ times ULN.

If 2 of the initial 6 patients experienced a DLT, additional 3 patients were to be enrolled at that dose level. If at least 3 of 6 patients experienced a DLT, the sponsor (Takeda Bio Development Center Ltd., Tokyo, Japan) was to discuss with the principal investigator-and with the Efficacy and Safety Evaluation Committee, if necessaryto determine whether the dose was intolerable or not.

If patients experienced any DLT during the first 28 days, treatment with trebananib was withheld and the patients were followed up until the resolution of the toxicity. If patients experienced infusion reactions, the infusion was interrupted or the infusion rate was slowed. If the infusion reaction persisted, sequential treatment with antihistamines and steroids was also allowed. Throughout the study, concomitant use of low-dose warfarin ( $\leq 1 \mathrm{mg} /$ day) or low molecular weight heparin for prophylaxis of thrombosis was allowed. Other treatments were not allowed during the study except for the supportive care the investigators considered necessary.

\section{Assessments}

Medical history was collected within 14 days before enrollment. Patients were hospitalized at least 5 days from day 1. Adverse events were monitored throughout the study and were graded according to the NCI CTCAE version 3.0. Blood pressure, pulse rate, and body temperature were measured at the following time points: predose and 1, 2, 6, 24,48 , and $96 \mathrm{~h}$ after starting the initial infusion at week 1 ; predose and $1 \mathrm{~h}$ after starting infusion at weeks 2-4; every week after week 6; and the end-of-study visit (i.e., 4 weeks after the end of treatment). Blood and urine samples for the laboratory tests were collected at the following time points: predose and 24, 48, and $96 \mathrm{~h}$ after starting the initial infusion; predose at weeks 2-4; every 4 weeks thereafter; and the end-of-study visit.

Serum samples for PK analysis were collected at the following time points: predose at weeks $1-4 ; 1,2,6,24,48$, and $96 \mathrm{~h}$ after starting infusion at week $1 ; 1,2,6,24,48$, 96,168 , and $264 \mathrm{~h}$ after starting infusion at week 4; every 4 weeks after week 8; and the end-of-study visit. Serum concentration of trebananib was determined by using a validated enzyme-linked immunosorbent assay [16, 17]. PK parameters were estimated by using non-compartmental methods with Phoenix WinNonlin software Version 6.1 (Pharsight Corporation, Mountain View, CA).

Serum samples for the assessment of anti-trebananib antibodies were also collected at the following time points: predose at weeks 1,2 , and 4 ; every 4 weeks thereafter; the end-of-study visit; and 8 weeks after the end of treatment. In the first analysis of this assessment, the presence/absence of anti-trebananib binding antibodies in serum was confirmed by using a validated acid-dissociation, bridging electrochemiluminescent immunoassay [17, 18]. Thereafter, all serum samples positive for antitrebananib binding antibodies were evaluated for potential neutralizing capabilities in a validated in vitro receptor binding assay [17].

Furthermore, serum samples were collected for the exploration of a biomarker at predose and $48 \mathrm{~h}$ after starting infusion at week 1 , predose at weeks 2 and 4 , every 4 weeks thereafter, and the end-of-study visit. As a potential biomarker, soluble vascular cell adhesion molecule-1 (sVCAM-1) was quantified by using a specific enzyme-linked immunosorbent assay kit (Quantikine ${ }^{\circledR}$; R\&D Systems Inc., Minneapolis, MN) following the manufacturer's instructions. VCAM-1 is involved in vascular remodeling, and variations in this biomarker may be indicative of a biological response to changes in the vascular endothelium [17]. 
Table 1 Demographic and baseline characteristics of the study patients

\begin{tabular}{|c|c|c|c|c|}
\hline & \multicolumn{4}{|c|}{ Trebananib dose cohort } \\
\hline & $3 \mathrm{mg} / \mathrm{kg}(n=6)$ & $10 \mathrm{mg} / \mathrm{kg}(n=6)$ & $30 \mathrm{mg} / \mathrm{kg}(n=6)$ & Total $(n=18)$ \\
\hline \multicolumn{5}{|l|}{ Sex, $n(\%)$} \\
\hline Male & $4(66.7)$ & $3(50.0)$ & $3(50.0)$ & $10(55.6)$ \\
\hline Female & $2(33.3)$ & $3(50.0)$ & $3(50.0)$ & $8(44.4)$ \\
\hline \multicolumn{5}{|l|}{ Age, years } \\
\hline Median (range) & $57.5(40-70)$ & $52.5(47-69)$ & $63.0(49-66)$ & $57.5(40-70)$ \\
\hline \multicolumn{5}{|l|}{ Weight, kg } \\
\hline Median (range) & $55.90(38.1-64.7)$ & $65.60(49.6-78.7)$ & $49.65(47.0-56.0)$ & $55.15(38.1-78.7)$ \\
\hline \multicolumn{5}{|c|}{ Primary tumor type, $n(\%)$} \\
\hline Gastric & $3(50.0)$ & $0(0.0)$ & $3(50.0)$ & $6(33.3)$ \\
\hline Rectal & $1(16.7)$ & $2(33.3)$ & $1(16.7)$ & $4(22.2)$ \\
\hline Pancreatic & $1(16.7)$ & $1(16.7)$ & $1(16.7)$ & $3(16.7)$ \\
\hline Colon & $1(16.7)$ & $1(16.7)$ & $0(0.0)$ & $2(11.1)$ \\
\hline Bladder & $0(0.0)$ & $0(0.0)$ & $1(16.7)$ & $1(5.6)$ \\
\hline Breast & $0(0.0)$ & $1(16.7)$ & $0(0.0)$ & $1(5.6)$ \\
\hline Uterine & $0(0.0)$ & $1(16.7)$ & $0(0.0)$ & $1(5.6)$ \\
\hline \multicolumn{5}{|c|}{$\begin{array}{l}\text { Eastern Cooperative Oncology Group } \\
\text { performance status, } n(\%)\end{array}$} \\
\hline 0 & $6(100.0)$ & $6(100.0)$ & $5(83.3)$ & $17(94.4)$ \\
\hline 1 & $0(0.0)$ & $0(0.0)$ & $1(16.7)$ & $1(5.6)$ \\
\hline
\end{tabular}

Tumor response was evaluated at week 8 and every 8 weeks thereafter by the investigators using computed tomography or magnetic resonance imaging and was classified according to the Response Evaluation Criteria in Solid Tumors (RECIST) 1.0 [19].

Statistical considerations

All data were summarized descriptively. Categorical variables are expressed as frequencies and percentages. Continuous variables are expressed as mean combined with standard deviation or median combined with range. All data were analyzed by using SAS $^{\circledR}$ System Version 9.1.3 (SAS Institute, Cary, NC).

\section{Results}

From June 2009 to April 2010, a total of 18 patients (6 for each dose cohort) were enrolled into the study. All patients received trebananib and were included in the safety and efficacy analysis. Of these, one patient in the $10-\mathrm{mg} / \mathrm{kg}$ cohort discontinued the study treatment because of disease progression during the DLT evaluation period. This patient was excluded from the DLT evaluation. At the time of data cutoff (January 17, 2012), 16 patients ended the study treatment because of disease progression and 2 patients were still receiving treatment. The median number of infusions was 5.5 (range, 4-113) for $3 \mathrm{mg} / \mathrm{kg}, 6.0$ (range, 1-17) for $10 \mathrm{mg} / \mathrm{kg}$, and 6.0 (range, 4-92) for $30 \mathrm{mg} / \mathrm{kg}$. The median cumulative dose was $16.50 \mathrm{mg} / \mathrm{kg}$ (range, $12.0-336.7 \mathrm{mg} / \mathrm{kg}$ ), $\quad 60.00 \mathrm{mg} / \mathrm{kg}$ (range, $10.0-170.0$ $\mathrm{mg} / \mathrm{kg}$ ), and $180.0 \mathrm{mg} / \mathrm{kg}$ (range, $120.0-2,760.0 \mathrm{mg} / \mathrm{kg}$ ), respectively.

Table 1 shows the demographic and baseline characteristics of the study patients. The median age was 57.5 (range, 40-70) years in the total population. Almost all patients $(94.4 \%)$ had ECOG performance status of 0 . The most common tumor types were gastric ( $n=6$; including 2 patients with gastrointestinal stromal tumors), rectal ( $n=4$; including one with rectal carcinoid), and pancreatic $(n=3)$.

Trebananib was tolerated at all dose levels. All patients had at least one adverse event, but no one discontinued the treatment because of adverse events. No DLTs were observed in any of the dose cohorts. Table 2 shows the common adverse events. The most common adverse events were peripheral edema, constipation, fatigue, and pyrexia. Grade 3 or greater adverse events were reported in 4 patients (one in the $3-\mathrm{mg} / \mathrm{kg}$ cohort, one in the $10-\mathrm{mg} / \mathrm{kg}$ cohort, and 2 in the $30-\mathrm{mg} / \mathrm{kg}$ cohort). Of these, the most frequently reported event was $\gamma$-glutamyltransferase increased $(n=4)$. No events with grade 3 or greater were considered treatment-related by the investigator.

Serious adverse events were reported in the following 3 patients: one in the $3-\mathrm{mg} / \mathrm{kg}$ cohort (ascites and pleural 
Table 2 Common adverse events occurring in at least 3 patients

\begin{tabular}{|c|c|c|c|c|c|c|c|c|}
\hline \multirow[t]{3}{*}{ Preferred term } & \multicolumn{8}{|c|}{ Trebananib dose cohort } \\
\hline & \multicolumn{2}{|c|}{$3 \mathrm{mg} / \mathrm{kg}(n=6)$} & \multicolumn{2}{|c|}{$10 \mathrm{mg} / \mathrm{kg}(n=6)$} & \multicolumn{2}{|c|}{$30 \mathrm{mg} / \mathrm{kg}(n=6)$} & \multicolumn{2}{|c|}{ Total $(n=18)$} \\
\hline & Any & $\geq$ Grade 3 & Any & $\geq$ Grade 3 & Any & $\geq$ Grade 3 & Any & $\geq$ Grade 3 \\
\hline Edema peripheral & $2(33)$ & $0(0)$ & $2(33)$ & $0(0)$ & $3(50)$ & $0(0)$ & $7(39)$ & $0(0)$ \\
\hline Constipation & $2(33)$ & $0(0)$ & $1(17)$ & $0(0)$ & $2(33)$ & $0(0)$ & $5(28)$ & $0(0)$ \\
\hline Fatigue & $3(50)$ & $0(0)$ & $1(17)$ & $0(0)$ & $1(17)$ & $0(0)$ & $5(28)$ & $0(0)$ \\
\hline Pyrexia & $2(33)$ & $0(0)$ & $1(17)$ & $0(0)$ & $2(33)$ & $0(0)$ & $5(28)$ & $0(0)$ \\
\hline Anorexia & $2(33)$ & $0(0)$ & $0(0)$ & $0(0)$ & $2(33)$ & $0(0)$ & $4(22)$ & $0(0)$ \\
\hline Diarrhea & $1(17)$ & $0(0)$ & $1(17)$ & $0(0)$ & $2(33)$ & $0(0)$ & $4(22)$ & $0(0)$ \\
\hline ECOG PS worsened & $3(50)$ & $0(0)$ & $0(0)$ & $0(0)$ & $1(17)$ & $0(0)$ & $4(22)$ & $0(0)$ \\
\hline$\gamma$-Glutamyl transferase increased & $1(17)$ & $1(17)$ & $1(17)$ & $1(17)$ & $2(33)$ & $2(33)$ & $4(22)$ & $4(22)$ \\
\hline Hypertension & $0(0)$ & $0(0)$ & $2(33)$ & $0(0)$ & $2(33)$ & $0(0)$ & $4(22)$ & $0(0)$ \\
\hline Abdominal distension & $2(33)$ & $0(0)$ & $0(0)$ & $0(0)$ & $1(17)$ & $0(0)$ & $3(17)$ & $0(0)$ \\
\hline Ascites & $2(33)$ & $0(0)$ & $0(0)$ & $0(0)$ & $1(17)$ & $0(0)$ & $3(17)$ & $0(0)$ \\
\hline Cancer pain & $1(17)$ & $0(0)$ & $1(17)$ & $0(0)$ & $1(17)$ & $0(0)$ & $3(17)$ & $0(0)$ \\
\hline Nausea & $1(17)$ & $0(0)$ & $0(0)$ & $0(0)$ & $2(33)$ & $0(0)$ & $3(17)$ & $0(0)$ \\
\hline Rash & $1(17)$ & $0(0)$ & $1(17)$ & $0(0)$ & $1(17)$ & $0(0)$ & $3(17)$ & $0(0)$ \\
\hline Stomatitis & $1(17)$ & $0(0)$ & $0(0)$ & $0(0)$ & $2(33)$ & $0(0)$ & $3(17)$ & $0(0)$ \\
\hline
\end{tabular}

ECOG PS Eastern Cooperative Oncology Group performance status

effusion), one in the $3-\mathrm{mg} / \mathrm{kg}$ cohort (subclavian vein thrombosis and cholecystitis), and one in the $30-\mathrm{mg} / \mathrm{kg}$ cohort (anorexia). Of these, cholecystitis was considered treatment-related because the patient did not have any complications, such as gallstones, which are known to be a cause of cholecystitis. Other events were not considered treatment-related by the investigator. Subclavian vein thrombosis was considered to be related to the central venous catheter that was placed in the patient.

Figure 1 shows serum concentration-time profiles of trebananib. The serum concentration of trebananib gradually declined after the completion of 1-hour infusion. After 4 once-weekly infusions, the serum concentrations increased slightly compared with those after the initial infusion. Table 3 shows the PK parameters of trebananib. Exposure to trebananib (maximum observed concentration $\left[C_{\max }\right]$ and area under the serum concentration-time curve from time 0 to $168 \mathrm{~h}$ post-dose $\left[\mathrm{AUC}_{0-168}\right]$ ) on both weeks 1 and 4 appeared to increase according to the dose administered. Serum clearance appeared to be similar across the dose levels with the mean total clearance ranging from 1.44 to $1.71 \mathrm{~mL} / \mathrm{h} / \mathrm{kg}$. The mean terminal-phase
Fig. 1 Serum concentrationtime curves of trebananib

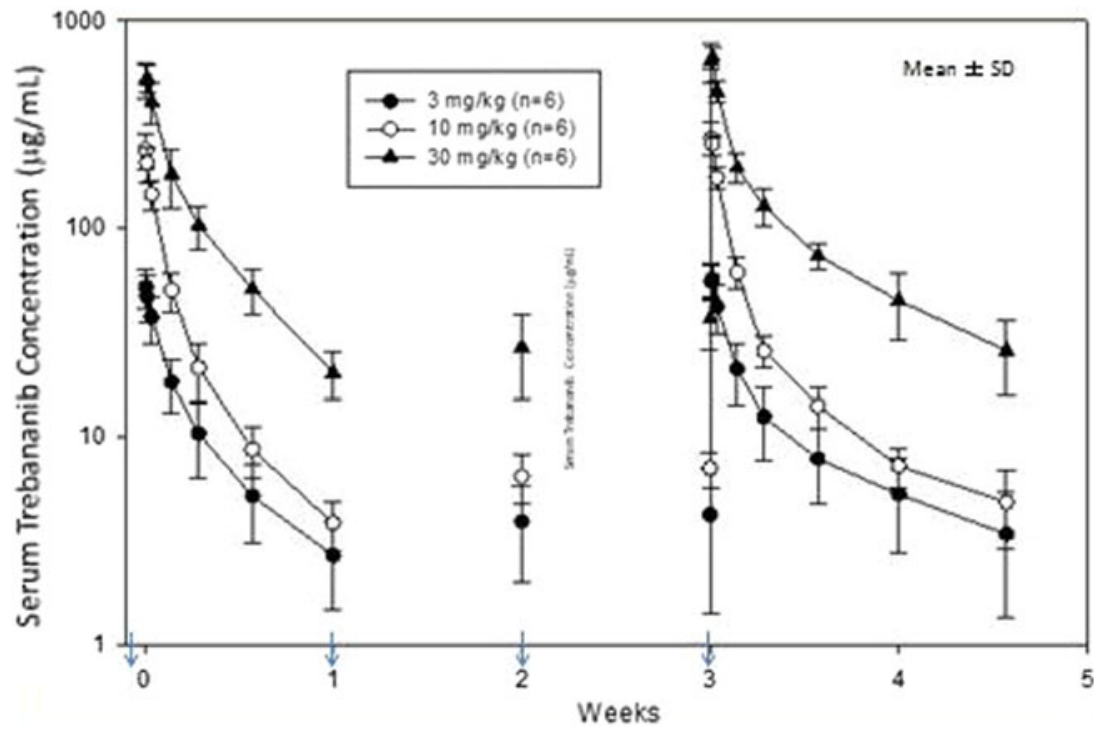

Arrow indicates dose admin istered 


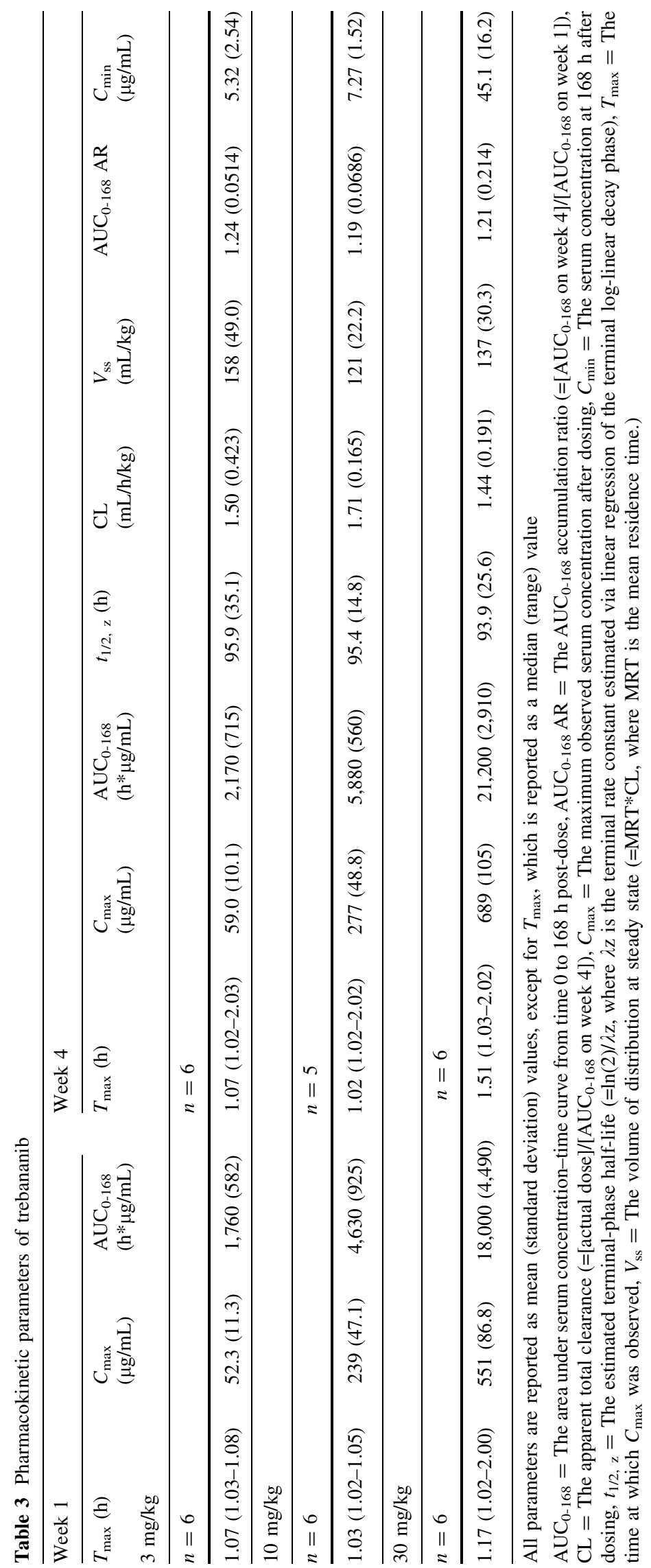



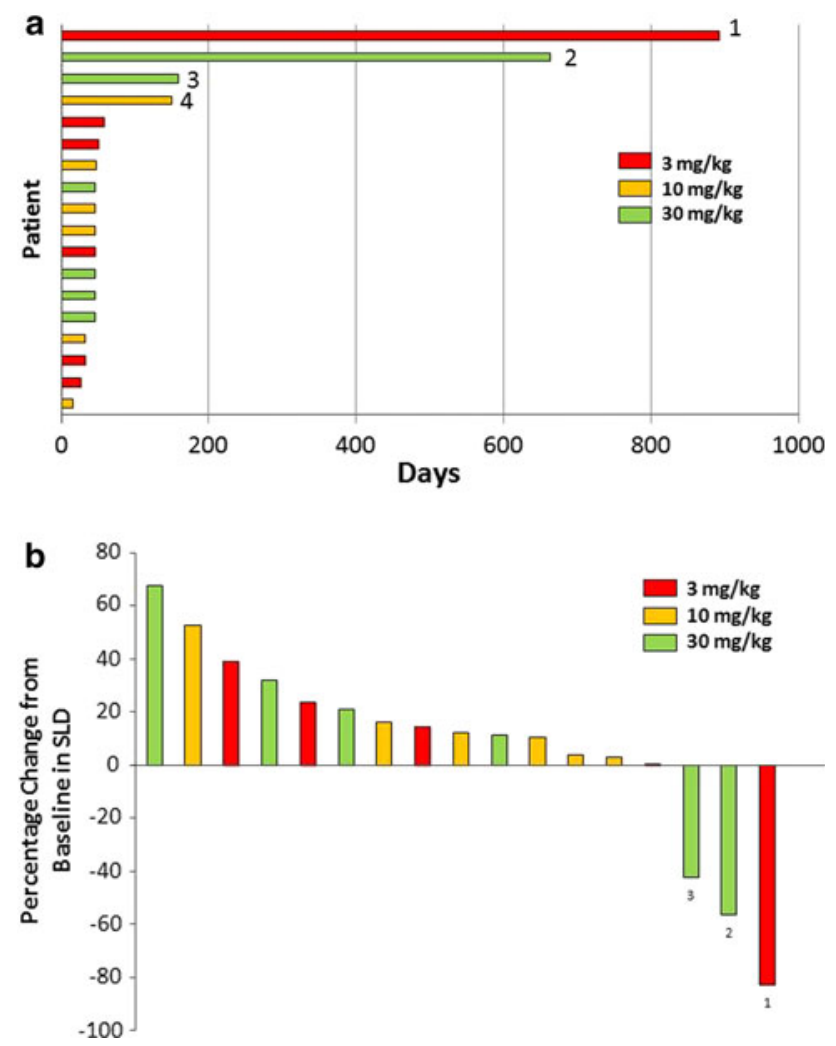

Fig. 2 Antitumor activity of trebananib. a Time to disease progression. Tumor type: 1 Colon, 2 Bladder, 3 Stomach (gastrointestinal stromal tumor), 4 Pancreas. b The maximum percent change in target lesions. SLD sum of the longest diameter. Tumor type: 1 Colon, 2 Bladder, 3 Stomach (gastrointestinal stromal tumor). One patient with colon cancer in the $3-\mathrm{mg} / \mathrm{kg}$ cohort and one with bladder cancer in the $30-\mathrm{mg} / \mathrm{kg}$ cohort had a best response of partial response

half-life ranged from 93.9 to $95.9 \mathrm{~h}$. Minimal accumulation was observed after multiple dosing with approximate 1.2 of the accumulation ratio of $\mathrm{AUC}_{0-168}$.

Anti-trebananib binding antibodies were detected in 2 patients at $3 \mathrm{mg} / \mathrm{kg}$ and one at $10 \mathrm{mg} / \mathrm{kg}$. However, no neutralizing antibodies were observed in their serum samples. Concentrations of sVCAM-1 transiently increased after the infusion according to the dose administered (data not shown).

Figure 2 shows the antitumor activity of trebananib. All patients had measurable diseases at baseline. One patient with colon cancer in the $3-\mathrm{mg} / \mathrm{kg}$ cohort and one with bladder cancer in the $30-\mathrm{mg} / \mathrm{kg}$ cohort had a best response of partial response. These 2 patients were on treatment at the time of data cutoff. The longest treatment period was over 2 years in the patient with colon cancer (Fig. 2a). One of 18 patients underwent computed tomography examination without receiving contrast agent at post-dose. Therefore, the tumor regions were not comparable between baseline and post-dose. As a result, 17 patients were included in the maximum percentage change in target lesions (Fig. 2b). No clinically meaningful relationship was observed between the concentrations of sVCAM-1 and tumor responses (data not shown).

\section{Discussion}

Results of our study show that weekly infusions of trebananib up to $30 \mathrm{mg} / \mathrm{kg}$ were tolerated without any treatment discontinuation because of adverse events. Adverse events were mild to moderate in most patients. No DLTs were observed. These results are consistent with those of the phase 1 single-agent study conducted in the United States [16]. In our study, the most common toxicities included peripheral edema and fatigue, which were also observed in the study conducted in the United States [16]. Of these, peripheral edema is a unique adverse event that has been considered to be related to trebananib [20]. No unexpected toxicities were reported.

The safety profile of trebananib was different from that of the VEGF/VEGFR pathway inhibitors, although both agents inhibit angiogenesis. Of the common toxicities associated with the VEGF-axis inhibitors, hypertension is the most prominent adverse event because the VEGF/ VEGFR pathway is a regulator of vasodilatation $[8,9]$. For example, grade $3 / 4$ hypertension occurred in $4-21 \%$ of patients who received the VEGF-axis inhibitors in the previous studies [21-23]. It is also a frequent reason to delay treatment [9]. In our study, although 4 patients experienced hypertension, these events were mild to moderate and did not require treatment discontinuation. No grade 3/4 hypertension was reported. Other common toxicities associated with VEGF-axis inhibitors such as proteinuria, hemorrhage, or thrombosis did not occur. Although subclavian vein thrombosis was reported in one patient, this event was considered to be related to the central venous catheterization. These distinct safety profiles of trebananib and the VEGF-axis inhibitors are probably derived from the fact that both agents inhibit angiogenesis in a completely different pathway and suggest that they may be combined to improve efficacy without significant overlapping toxicities.

In the PK data of our study, dose-dependent exposure and minimal accumulation of trebananib after 4 onceweekly infusions were observed. These results are consistent with those of the phase 1 studies in the United States [16, 17], and estimated values of PK parameters were similar among the studies. For example, the mean serum clearance ranged from 1.44 to $1.71 \mathrm{~mL} / \mathrm{h} / \mathrm{kg}$ in our study, whereas it ranged from 0.70 to $1.27 \mathrm{~mL} / \mathrm{h} / \mathrm{kg}$ in the previous single-agent study [16]. In addition, the mean $C_{\max }$ 
after 4 once-weekly infusions of $10-\mathrm{mg} / \mathrm{kg}$ trebananib was $277 \mu \mathrm{g} / \mathrm{mL}$ in our study, $249 \mu \mathrm{g} / \mathrm{mL}$ in the single-agent study [16], and $219 \mu \mathrm{g} / \mathrm{mL}$ in the study combined with chemotherapies [17]. These results suggest the absence of ethnic difference in the PK profile of trebananib when intravenously administered weekly.

Although anti-trebananib binding antibodies were detected in 3 patients in our study, no neutralizing antibodies were detected. The previous studies have provided similar results and have also shown that the anti-trebananib antibodies had no apparent effect on serum trebananib concentrations [16, 17]. From these results, we consider that the immune response induced by multiple dosing of trebananib is unlikely to affect the exposure.

In the efficacy analysis, trebananib showed evidence of antitumor activity. Two patients, one with colon cancer and the other with bladder cancer, achieved a partial response. Both of them had a durable partial response and were on treatment at the time of data cutoff. In the previous singleagent study conducted in the United States, of 29 patients with evaluable tumor response, one patient with advanced ovarian cancer refractory to multiple chemotherapies had a partial response with the dose of $30 \mathrm{mg} / \mathrm{kg}$ [16]. These results suggest the efficacy of trebananib as monotherapy. Although concentrations of sVCAM-1 transiently increased in a dose-dependent manner, no clinically meaningful relationship was observed between the concentrations of sVCAM-1 and tumor responses. Further efforts may be warranted, because selecting suitable biomarkers for angiopoietin/Tie2 axis is still challenging [17].

In conclusion, trebananib was tolerated and showed acceptable safety profile in Japanese patients with advanced solid tumors. These results are consistent with those of the phase 1 single-agent study conducted in the United States. The PK parameters in Japanese were also similar to those obtained in the previous studies in the United States. These results suggest the absence of ethnic difference. Furthermore, trebananib showed evidence of durable antitumor activity in some patients. To confirm the favorable profiles of trebananib, further clinical trials including randomized controlled trials are needed. At present, several trials that evaluate the efficacy and safety of trebananib in combination with either VEGF-axis inhibitors or chemotherapies are in progress [24]. These programs include 3 phase 3 clinical trials in patients with ovarian cancer (TRINOVA-1, TRINOVA-2 and TRINOVA-3; ClinicalTrials.gov NCT01204749, NCT01281254 and NCT 01493505, respectively).

Acknowledgments We thank the study coordinators, nurses, and patients involved in the study; Don Zhong (Amgen Inc., Thousand Oaks, CA) for anti-trebananib antibody analysis; Yoshikazu Kobayashi (Takeda Bio Development Center Ltd., Tokyo, Japan) for assistance with the preparation of the manuscript; and Kenichi Hayashi (Alamedic Co., Ltd., Tokyo, Japan) for writing assistance.
Conflict of interest This study was sponsored by Takeda Bio Development Center Ltd. Kazuhiro Shibayama and Takatoshi Takubo are employees of Takeda Bio Development Center Ltd. David M. Weinreich was an employee as leadership position and owned stock of Amgen Inc. The other authors have no conflict of interest.

Open Access This article is distributed under the terms of the Creative Commons Attribution License which permits any use, distribution, and reproduction in any medium, provided the original author(s) and the source are credited.

\section{References}

1. Fidler IJ, Kerbel RS, Ellis LM (2001) Biology of cancer: angiogenesis. In: Devita VT, Hellman S, Rosenberg SA (eds) Cancer: principles and practice of oncology. Lippincott-Raven Publishers, Philadelphia, pp 137-147

2. Leek RD (2001) The prognostic role of angiogenesis in breast cancer. Anticancer Res 21:4325-4331

3. Carmeliet P (2000) Mechanisms of angiogenesis and arteriogenesis. Nat Med 6:389-395

4. Scappaticci FA (2002) Mechanisms and future directions for angiogenesis-based cancer therapies. J Clin Oncol 20:3906-3927

5. Dvorak HF (2002) Vascular permeability factor/vascular endothelial growth factor: a critical cytokine in tumor angiogenesis and a potential target for diagnosis and therapy. J Clin Oncol 20:4368-4380

6. Ferrara N, Gerber HP, LeCouter J (2003) The biology of VEGF and its receptors. Nat Med 9:669-676

7. Veeravagu A, Hsu AR, Cai W, Hou LC, Tse VC, Chen X (2007) Vascular endothelial growth factor and vascular endothelial growth factor receptor inhibitors as anti-angiogenic agents in cancer therapy. Recent Pat Anticancer Drug Discov 2:59-71

8. Eskens FA, Verweij J (2006) The clinical toxicity profile of vascular endothelial growth factor (VEGF) and vascular endothelial growth factor receptor (VEGFR) targeting angiogenesis inhibitors: a review. Eur J Cancer 42:3127-3139

9. Roodhart JM, Langenberg MH, Witteveen E, Voest EE (2008) The molecular basis of class side effects due to treatment with inhibitors of the VEGF/VEGFR pathway. Curr Clin Pharmacol 3:132-143

10. Yu Y, Varughese J, Brown LF, Mulliken JB, Bischoff J (2001) Increased Tie2 expression, enhanced response to angiopoietin-1, and dysregulated angiopoietin-2 expression in hemangiomaderived endothelial cells. Am J Pathol 159:2271-2280

11. Bach F, Uddin FJ, Burke D (2007) Angiopoietins in malignancy. Eur J Surg Oncol 33:7-15

12. Maisonpierre PC, Suri C, Jones PF et al (1997) Angiopoietin-2, a natural antagonist for Tie2 that disrupts in vivo angiogenesis. Science 277:55-60

13. Ahmad SA, Liu W, Jung YD et al (2001) The effects of angiopoietin-1 and -2 on tumor growth and angiogenesis in human colon cancer. Cancer Res 61:1255-1259

14. Coxon A, Bready J, Min H et al (2010) Context-dependent role of angiopoietin-1 inhibition in the suppression of angiogenesis and tumor growth: implications for AMG 386, an angiopoietin-1/2neutralizing peptibody. Mol Cancer Ther 9:2641-2651

15. Oliner J, Min H, Leal J et al (2004) Suppression of angiogenesis and tumor growth by selective inhibition of angiopoietin-2. Cancer Cell 6:507-516

16. Herbst RS, Hong D, Chap L et al (2009) Safety, pharmacokinetics, and antitumor activity of AMG 386, a selective angiopoietin inhibitor, in adult patients with advanced solid tumors. J Clin Oncol 27:3557-3565 
17. Mita AC, Takimoto CH, Mita M et al (2010) Phase 1 study of AMG 386, a selective angiopoietin 1/2-neutralizing peptibody, in combination with chemotherapy in adults with advanced solid tumors. Clin Cancer Res 16:3044-3056

18. Zhong ZD, Dinnogen S, Hokom M et al (2010) Identification and inhibition of drug target interference in immunogenicity assays. J Immunol Methods 355:21-28

19. Therasse P, Arbuck SG, Eisenhauer EA et al (2000) New guidelines to evaluate the response to treatment in solid tumours. J Natl Cancer Inst 92:205-216

20. Karlan BY, Oza AM, Richardson GE et al (2012) Randomized, double-blind, placebo-controlled phase II study of AMG 386 combined with weekly paclitaxel in patients with recurrent ovarian cancer. J Clin Oncol 30:362-371
21. Hurwitz H, Fehrenbacher L, Novotny W et al (2004) Bevacizumab plus irinotecan, fluorouracil, and leucovorin for metastatic colorectal cancer. N Engl J Med 350:2335-2342

22. Escudier B, Eisen T, Stadler WM et al (2007) Sorafenib in advanced clear-cell renal-cell carcinoma. N Engl J Med 356: $125-134$

23. Hecht JR, Trarbach T, Hainsworth JD et al (2011) Randomized, placebo-controlled, phase III study of first-line oxaliplatin-based chemotherapy plus PTK787/ZK 222584, an oral vascular endothelial growth factor receptor inhibitor, in patients with metastatic colorectal adenocarcinoma. J Clin Oncol 29:1997-2003

24. Robson EJ, Ghatage P (2011) AMG 386: profile of a novel angiopoietin antagonist in patients with ovarian cancer. Expert Opin Investig Drugs 20:297-304 